\title{
Vanilla bicolor Lindl. (Orchidaceae) from the Peruvian Amazon: auto-fertilization in Vanilla and notes on floral phenology
}

\author{
Alex R. Van Dam • J. Ethan Householder • \\ Pesach Lubinsky
}

Received: 22 July 2009/Accepted: 8 February 2010/Published online: 5 March 2010

(C) The Author(s) 2010. This article is published with open access at Springerlink.com

\begin{abstract}
Minimal documentation exists for natural pollination in wild Vanilla spp., despite the economic importance of this genus, additionally commercial vanilla ( $V$. planifolia Jacks.) is one of very few crops whose production depends entirely on artificial pollination. Flowering and fruiting phenology of Vanilla bicolor Lindl., a close relative of $V$. planifolia, was documented in a palm swamp in the Peruvian Amazon. V. bicolor was found to autofertilize via bagging experiments. This ecotype had an average fruit set per raceme of $42.50 \pm 2.5 \%$. Pollen removal experiments suggest that stigmatic leak may be the mechanism by which auto-pollination occurs in $V$. bicolor.
\end{abstract}

A. R. Van Dam

Department of Entomology, University of California, Riverside, CA 92521-0124, USA

J. E. Householder

Botanical Research Institute of Texas (BRIT),

509 Pecan St., Fort Worth, TX 76102, USA

P. Lubinsky

Department of Botany and Plant Sciences, University of California, Riverside, CA 92521-0124, USA

\section{A. R. Van Dam $(\bowtie)$}

Department of Animal Science, University of California Davis, One Shields Avenue, Davis, CA 95616, USA

e-mail: vandama01@gmail.com
Keywords Aguajales - Auto-pollination · Orchidaceae · Palm swamps · Phenology · Self-fertilization · Vanilla

Scant documentation exists on pollination mechanisms in wild Vanilla species (Lubinsky et al. 2006). With vanilla being a crop of global significance surprisingly little attention has been paid to its wild relatives for crop improvement. Recent work demonstrating historical plant breeding and crop development via hybridization opens a new window onto the possibilities of crop improvement in vanilla (Lubinsky et al. 2008a). Vanilla cultivation relies upon the use of cheap labor to carry out hand pollination in order to obtain fruits for the spice trade, and this results in vanilla being an expensive crop (Lubinsky et al. 2006). Understanding pollination in this economically valuable genus is of currency.

Vanilla displays considerable reproductive diversity both between and within species (Cameron and Soto Arenas 2003). Few studies have documented the natural mechanisms of pollination, phenology, and seed dispersal of Vanilla despite its economic importance (Lubinsky et al. 2006; Householder 2007). Recently, Euglossine bees have been shown to pollinate and disperse the seeds of $V$. pompona subsp. grandiflora Lindl. in the neotropics (Lubinsky et al. 2006). Furthermore, natural hybridization seems to have occurred in several neotropical Vanilla spp. (Nielsen 2000; Lubinsky et al. 2008a). In addition to 
out-crossing and asexual propagation, auto-pollination has also been reported in Vanilla (van der Pijl and Dodson 1966). Examples of species that are thought to auto-pollinate, as evidenced by their high fruit sets, atypical in outcrossing species, are V. palmarum (Salzm. ex Lindl.) Lindl., V. savannarum Britton, and V. griffithii Rchb. f. (Cameron and Soto Arenas 2003). The mechanisms and concomitant selective pressures for auto-pollination in Vanilla remain unclear at best.

There are three proposed mechanisms for autopollination in Vanilla: (1) "stigmatic leak" by which stigma lobes release a fluid, that contacts the pollen and induces germination of the pollen tubes (van der Pijl and Dodson 1966), (2) by dehydration or underdevelopment of the rostellum, which could also allow for pollen to contact the stigmatic cavity (Garay and Sweet 1974), (3) a third mechanism of self-fertilization in Vanilla that has remained over looked is agamospermy. In the Neuwiedia veratrifolia Blume (Apostasioideae) the method of selfpollination was determined to be auto-pollination not agamospermy via emasculation experiments (Okada et al. 1996; Kocyan and Endress 2001). Thus, auto-pollination is the method of self-fertilization that occurs at the clade sister to the rest of Orchidaceae. Documentation of any of the above three mechanisms remain absent in Vanilla.

Vanilla bicolor Lindl. is a widespread locally common hemi-epiphyte endemic to the Neotropics (Christenson 1995). They are found in open swampy areas along rivers in northern South America and exposed humid thickets along mountain crests in the Carribean (Adams 1972; Werkhoven 1986; Christenson 1995; Borhidi 1996). V. bicolor is a close relative of the widely cultivated $V$. planifolia Jacks (Cameron and Soto Arenas 2003; Lubinsky et al. 2008a) making it an important wild relative. Unlike the exceedingly sparse density of wild V. planifolia plants (Lubinsky et al. 2006, 2008a, b) V. bicolor occur at high densities in southern Peru and we were curious if higher density resulted in higher pollination rate due to increased reward. In this short communication we provide evidence regarding the floral phenology, pollination syndrome (i.e., outcrossing or self-fertilization) and possible mechanism of pollination in a cleistogamous ecotype of $V$. bicolor from the Southern Peruvian Amazon.

\section{Materials and methods}

Study site

Our study site is located in southeastern Peru in the Madre de Díos basin (Fig. 1). The Madre de Díos River is located in the headwaters of the southwest Amazon, draining a portion of the forelands of the Eastern Cordillera. The Madre de Díos River displays high rates of lateral migration and typical meander scroll morphology. Over 300 hundred wetlands occur along the current Madre de Dios River floodplain, generally hugging the terrace escarpments. Some wetlands in particular, palm swamps, are known locally as "aguajales", named after the common name of the monodominant palm Mauritia flexuosa L. Carrera, or "aguaje". Aguajales in this region range in size from 1 to 2,000 ha, occupying a significant portion of ecologically important floodplain habitat. Wetland soils are permanently saturated year round, fed by perennial spring inputs (personal obsvervation, Householder 2007).

Annual average rainfall in the region where our study occurred is $2,995 \pm 455 \mathrm{~mm}$. Rainfall is unevenly distributed throughout the year, with greater than $80 \%$ falling between October and April. Average temperature fluctuates minimally between 21 and $26^{\circ} \mathrm{C}$, however southerly cold fronts rapidly progress northward from Patagonia, known as "friajes" and are common in June through August (Amazon Conservation Association, unpublished data). These friajes are known to decrease temperatures to $10^{\circ} \mathrm{C}$ or less in a matter of minutes. Climate data since 2001 is publicly available provided by the Amazon Conservation Association (ATRIUM 2007).

Data was collected on $V$. bicolor in the Peruvian Amazon near the Los Amigos research station in the center of an aguajale (palm swamp) ( $12^{\circ} 33.453^{\prime}$ $\mathrm{W} 70^{\circ} 07.312^{\prime}$ at $\sim 330 \mathrm{~m}$ ). We set up a $50 \times 55 \mathrm{~m}$ plot in which phenological data (excluding the frequency of bloom and auto-fertilization tests which were recorded in the same aguajal but outside of the plot) for $V$. bicolor vines were recorded during August 17-18, 2005. Most plants had finished blooming during this time of the year in August during the dry season. 
Fig. 1 Map of Madre de Dios River Peru in grey with aguajales shown in color transposed over rainfall isohyets from Sombroek (2001)

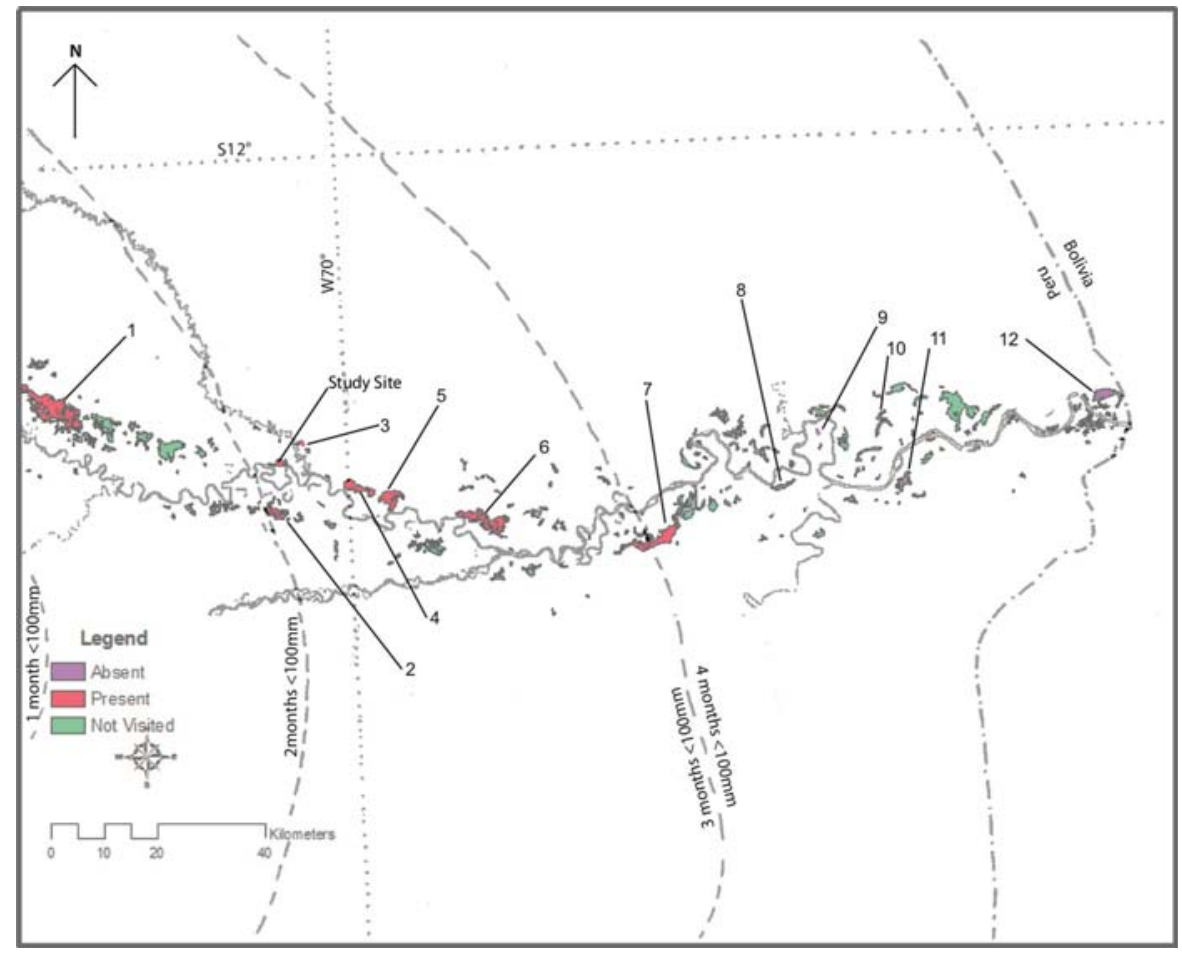

Rate of fruit set in $V$. bicolor

Multiple individuals of $V$. bicolor plants are commonly encountered climbing up sides of palm trees (Mauritia flexuosa). We will refer to multiple $V$. bicolor vines growing up the sides of a single palm tree as a "clump". We counted the number of vines per clump of $V$. bicolor, the number of individual racemes of $V$. bicolor per clump, the number of un-pollinated flowers per raceme, the number of pollinated flowers per raceme, and the number of buds or new flowers per raceme. An un-pollinated flower was recognized by the presence of a bract on the raceme, but lacking a flower or a fruit as abscission of flowers occurs. A pollination event was also denoted by the presence of fruit on a raceme or a flower with a drooping ovary. The height at which each raceme occurred was measured.

The average fruit set per raceme, number of racemes per clump of $V$. bicolor, average height of the racemes occurring on the $V$. bicolor vines, and percent of $V$. bicolor vines that did not produce racemes were calculated. Only racemes that had no new buds and completely finished blooming were used for calculating the fruit set rate. A total of 131 racemes from 49 clumps of $V$. bicolor growing up palm tree trunks occurred in our study plot.

Fruit set data was tested for a normal distribution by looking at a scatter plot of residuals using SYSTAT Version $9.01^{\circledR}$ SPSS Inc.1998. Residual scatter plots were made for the height of individual racemes to their fruit set rate, and fruit set rate to number of clumps of $V$. bicolor growing over individual palm trees in our study site. Scatter plots of the residuals were both normal so the next step was to perform a linear regression analysis on the data to see if any trends existed. Finally trend lines were plotted for the linear regression analyses using Microsoft Excell ${ }^{\circledR} 2004$ edition. Linear regression analyses were conducted to see if any immediate phenological patterns stood out as well as to add to documentation of the floral phenology for comparisons between any future studies. Height of racemes and their density have been correlated with increased pollinator visitation in some plants (Pyke et al. 1977; Engel and Irwin 2003). We were also curious if these tests might point toward any possible effects of pollinators on $V$. bicolor floral phenology. Finally histograms were constructed from the data collected. 
Auto-fertilization tests

Auto-fertilization in $V$. bicolor was determined two ways (1) an intensive survey across the entire Los Amigos aguajal for open or partially open flowers was conducted on August 22, 2005, 17 cleistogamous flowers that showed recent evidence of fertilization (1-2 days previous) via drooping ovaries were inspected for pollen removal or pollen granules placed on the stigma (2) 10 racemes of 10 different $V$. bicolor plants were bagged with Wirlpak ${ }^{\circledR}$ plastic bags. Bags excluded any pollinators from entering the flowers. Fertilization was determined by presence of developing fruits. The following dry season in April of 200613 additional racemes from 13 different plants were bagged in a similar manner using $1 \mathrm{~mm}$ mesh net to prevent any possible temperature differences between bagged flowers and outside environment. Plants to bag were chosen based on presence of flowers and accessibility from the $50 \times 55$ plot.

To test for agamospermy, ten flowers from different racemes and plants had their pollen removed by hand before completion of flower development. Racemes along with removed flowers were bagged with $1 \mathrm{~mm}$ mesh nets and allowed to mature. They were later checked once flowers had finished blooming. Manipulated buds were periodically monitored until either fruit development began, suggesting agamospermy, or senescing flowers fell from the raceme, indicating unsuccessful pollination.

\section{Frequency of bloom in $V$. bicolor}

Time between blooms in $V$. bicolor was calculated by recording the number of days from one flower opening to another for 10 racemes from 10 different individuals. Plants were observed daily at approximately 9:00 am for 3 weeks from August 10 to August 31, 2005. Time between blooms varied from plant to plant slightly. A bloom was counted as stereotypical closed florescence in which flowers were only slightly open (Fig. 2a). One pre-dawn and post-dusk observation was made in which five plants were watched to see if buds opened at night, but a nocturnal bloom was not observed, instead buds partially opened in morning (Fig. 2a). Flowers were also observed throughout the wet season (NovemberApril) to look for any different trends in florescence production.
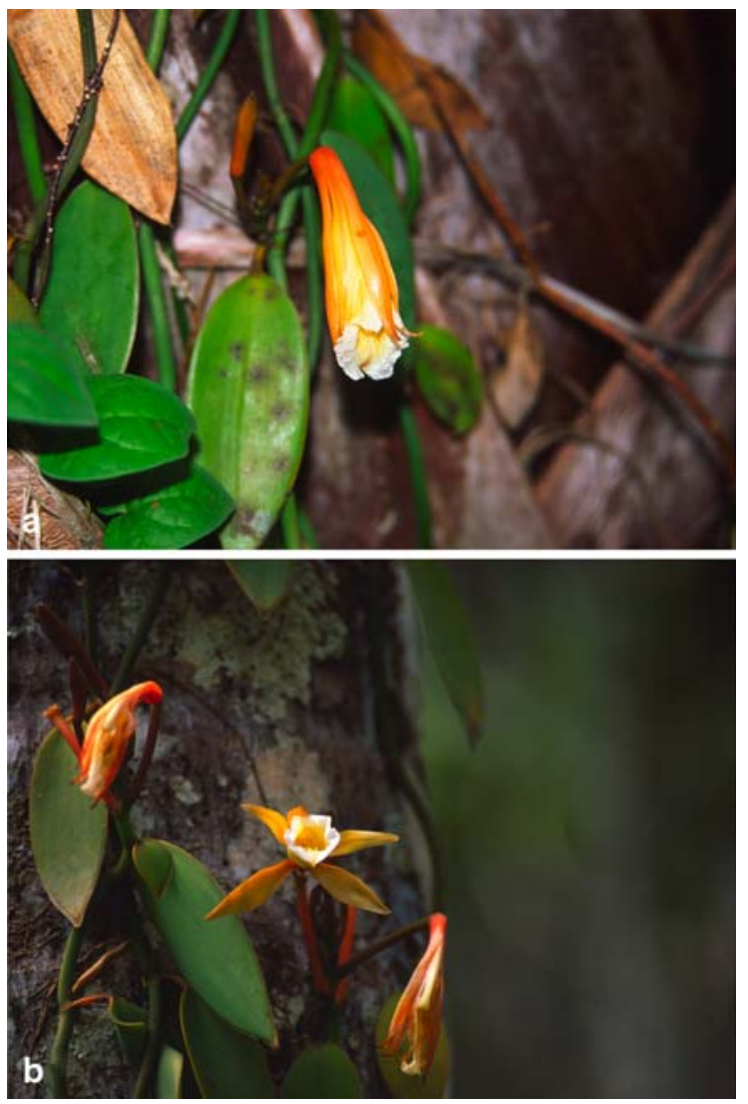

Fig. 2 a Top: Vanilla bicolor exhibiting the typical cleistogamous state that was encountered at our study site in the Peruvian Amazon $\left(\mathrm{S} 12^{\circ} 33.453^{\prime} \mathrm{W} 70^{\circ} 07.312^{\prime}\right.$ at $\left.\sim 330 \mathrm{~m}\right)$. b Below: Vanilla bicolor exhibiting the atypical open florescence found at our study site

Survey for $V$. bicolor in aguajales of Madre de Dios Peru

Thirteen different aguajales in the Madre de Dios Province of the Peruvian Amazon were surveyed for presence or absence of various Vanilla spp. The presence or absence of $V$. bicolor was noted as well as the growing condition. This was done to learn more about the preferred habitat of $V$. bicolor. This was an exhaustive survey covering 13 different aguajales over a $300 \mathrm{~km}$ stretch of the Madre de Dios drainage system in Peru. An Arc GIS map of the survey was constructed. Based on field experience it seemed that eastern aguajales lacked $V$. bicolor. To look for a possible explanation to this pattern the GIS map was transposed onto rainfall isohyte maps from 
Sombroek (2001) to see if any rainfall and dry season intensity patterns of the region affected where $V$. bicolor grew. Upon constructing this map it was clear that $V$. bicolor was absent from aguajales of southern Peru that characteristically receive less than 4 months out of the year with $<100 \mathrm{~mm}$ per month, thus a measure of dry season intensity. This was followed by a linear regression analysis to see if a relationship existed between presence and absence data and intensity of the dry season using Microsoft Excell $^{\circledR} 2004$.

\section{Results}

Rate of fruit set in V. bicolor

A summary of all results of rate of fruit set is given on Table 1. Average rate of fruit set per raceme was $42.50 \pm 2.50 \% \quad(N=131), 0-100 \%$ fruit set per raceme (Table 1; Fig. 3a). Average number of racemes per clump of $V$. bicolor was $5.10 \pm 0.68$ $(N=41)$ with the range being 1-16 racemes per clump of $V$. bicolor (Table 1; Fig. 3b). Average height of a raceme was $3.14 \pm 0.07 \mathrm{~m}(N=253)$ with a range from .2 to $6.1 \mathrm{~m}$ in height (Table 1) (Fig. 3c). Average number of florets per raceme was $5.25 \pm 0.18 \quad(N=131) \quad$ range $1-13 \quad$ (Table 1 ; Fig. 3d). Percentage of plants that were not in bloom during the flowering season recorded was $16.7 \%$ (8 of 48) from our study site (Table 1).

Result from the linear regression analysis between height of a raceme and its pollination rate was not significant $(P=0.961$; Fig. $4 a)$. This indicates that there is no relationship between the height of a raceme and its pollination rate. Linear regression analysis between fruit set rate per raceme and number of $V$. bicolor racemes growing per clump of $V$. bicolor were not significant as well $(P=0.112$; Fig. 4b). Thus there was no trend in fruit set rate and number of racemes per clump of $V$. bicolor.

\section{Auto-fertilization tests}

After visually inspecting 17 recently fertilized flowers all 17 had no pollen removed or pollen placed on stigma area. Furthermore all of these flowers had fully developed rostellums and were not dry or shriveled in any way suggesting that auto-pollination via "stigmatic leak" or agamospermy are possible mechanisms for auto-fertilization. Results from bagged racemes from the August experiment was that 3 out of 10 bagged racemes developed fruit. These results indicate that self-fertilization is occurring in this population. Results from the April 2006 bagging experiment that included 13 racemes on different plants lend further support to this conclusion. Eighty-five percent of bagged racemes developed fruit. Seventy-one percent of all flowers developed fruit under bagged conditions in the April 2006 experiment. This again indicates that selffertilization is occurring in this population.

Pollen removal experiments concluded that no flowers became pollinated after pollen was removed, thus agamospermy may not be a method by which this species may self-fertilize and auto-pollination is perhaps the method for self-fertilization. This sample size (10 flowers) is rather small, but it does suggest
Table 1 Summary of phenological data compiled on V. bicolor in an aguajale (palm swamp) in the Peruvian Amazon $\left(\mathrm{S} 12^{\circ} 33.453^{\prime} \mathrm{W} 70^{\circ} 07.312^{\prime}\right.$ at $\left.\sim 330 \mathrm{~m}\right)$ from a $50 \times 55 \mathrm{~m}$ plot in which all $V$. bicolor "clumps" (multiple tangled vines of $V$. bicolor) were growing on palm trees (Mauritia flexuosa)

\begin{tabular}{llll}
\hline Phenological category & $\mu \pm$ SE & Range & $N$ \\
\hline Average fruit set/raceme & $42.50 \pm 2.5 \%$ & $(0-100 \%)$ & $N=131$ \\
Average number of florets/raceme & $5.25 \pm 0.18$ & $(1-13)$ & $N=131$ \\
Average number of racemes/clump & $5.10 \pm 0.68$ & $(1-16)$ & $N=41$ \\
Average raceme height & $3.14 \pm 0.07 \mathrm{~m}$ & $(0.2-6.1 \mathrm{~m})$ & $N=253$ \\
$\%$ V. bicolor clumps on palms not blooming & $16.67 \%$ & 0 & $N=8$ \\
Days between a single bloom & 5 days & 0 & $N=10$ \\
\hline
\end{tabular}

Means are followed by standard error 
a
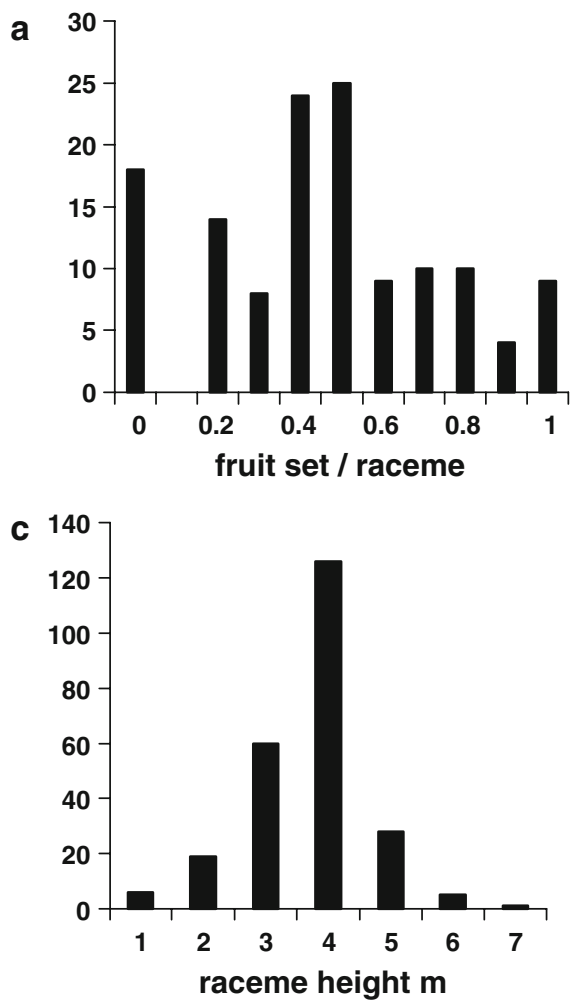

Fig. 3 Histograms of phenological data compiled on $V$. bicolor in an aguajale (palm swamp) in the Peruvian Amazon $\left(\mathrm{S} 12^{\circ} 33.453^{\prime} \mathrm{W}^{\circ} 0^{\circ} 07.312^{\prime}\right.$ at $\left.\sim 330 \mathrm{~m}\right)$ from a $50 \times 55 \mathrm{~m}$

that agamospermy is not a mechanism affecting autopollination.

\section{Frequency of bloom in $V$. bicolor}

There was a single bloom for each florescence at 5-day intervals per raceme, although variation on this would be expected with a larger sample size. Each flower was only open or slightly open for a single day at a time. Over the duration of the blooming season from August to mid-September only one individual flower (Fig. 2b) was fully open out of 68 cleistogamous flowers (Fig. 2a) that were observed blooming across the aguajale. Thus an estimated $98.5 \%$ of flowers during the dry season exhibit a cleistogamous appearance. Cleistogamy is a common characteristic of auto-pollination in the Orchidaceae (Catling 1990). Furthermore there is no evidence of cross-pollination in cleistogamous flowers in the Orchidaceae (Catling 1990). b 10

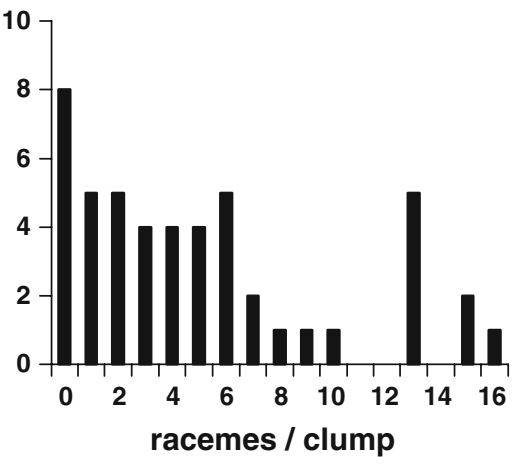

d

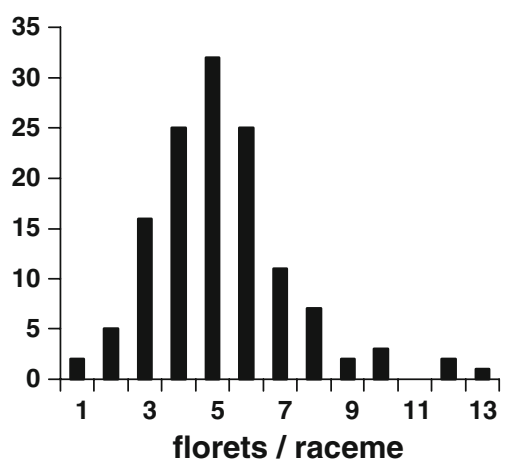

plot in which all $V$. bicolor "clumps" (multiple tangled vines of $V$. bicolor) were growing on palm trees (Mauritia flexuosa)

Survey for $V$. bicolor in aguajales of Madre de Dios Peru

Across thirteen aguajales sampled for $V$. bicolor a distinct geographical trend emerged. In eastern most aguajales $V$. bicolor was absent (Fig. 1). Size of aguajal did not seem to affect presence or absence of this species because relatively large and small aguajales both contained $V$. bicolor. Furthermore after transposing rainfall isohyte data from Sombroek (2001) onto the GIS map of aguajales combined with presence or absence data of $V$. bicolor distributions it was clear that intensity of the dry season prohibits this species from growing farther eastward (Fig. 1). Specifically the cut off point seemed to be in areas with $<100 \mathrm{~mm}$ of rainfall for more than 4 months out of the year prohibiting the growth of $V$. bicolor (Fig. 1). Results from the linear regression analysis clearly indicate that the intensity of the dry season is related to where $V$. bicolor can grow in the aguajales of southern Peru $\left(d f=12 ; R^{2}=0.606 ; P=2 \mathrm{E}^{-3}\right)$. 

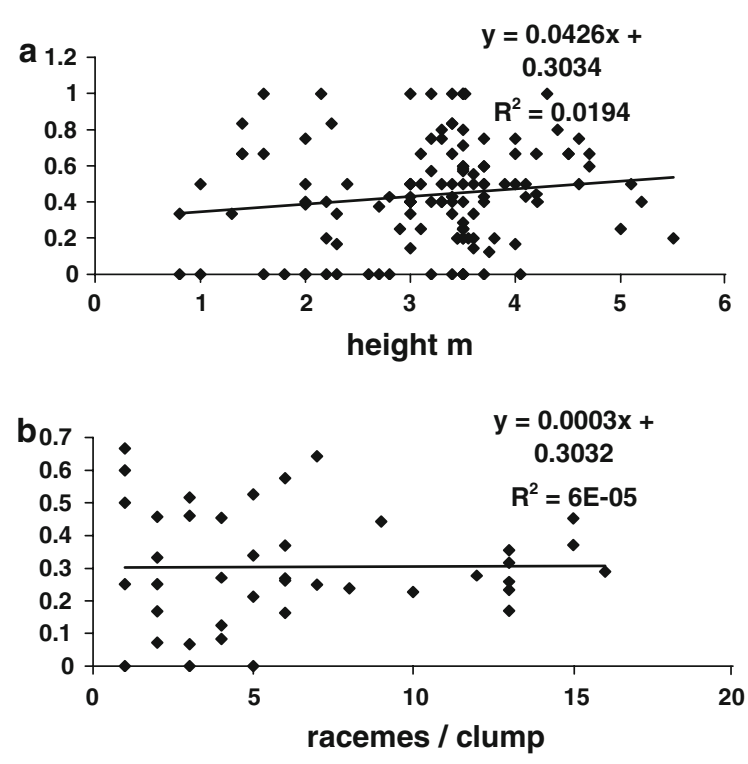

Fig. 4 Scatter plots with linear regression trend lines. The slope of the linear regression followed by the $R^{2}$ value are given in the top right hand corner of each linear regression analysis. a Top: $V$. bicolor fruit set/raceme plotted against height of raceme. b Below: $V$. bicolor average fruit set/clump plotted against racemes/clump

Hopefully future more detailed isohyte data will be available to test our observations as data provided here is a rough fitting of regional rainfall patterns.

\section{Discussion}

Auto-fertilization in $V$. bicolor

Several lines of evidence illuminate auto-fertilization as a method by which $V$. bicolor in our study site can reproduce. The combination of a high fruit set, ubiquity of closed flowers during the dry season, and fertilization of bagged flowers, all point toward autofertilization. Furthermore the pollination rate for this auto-fertilizing $V$. bicolor is high compared to other Vanilla species that are Euglossine pollinated such as $V$. pompona subsp. grandiflora (Lubinsky et al. 2006), which has a pollination rate of $\sim 1 \%$ (personal observation, Householder 2007). Other populations of $V$. bicolor may exhibit a non-cleistogamous phenotype (see Christenson 1995). Furthermore we provide some initial evidence that the method of autofertilization may be auto-pollination and not agamospermy through emasculation experiments. Also morphological examination of $V$. bicolor flowers shows a fully developed rostellum in pollinated flowers making "stigmatic leak" the most likely mechanism of auto-pollination in this species.

Drought conditions may eliminate $V$. bicolor from aguajales under certain circumstances thus reducing the Vanilla and consequent plant diversity in those aguajales (Fig. 1). Meteorological evidence from the Amazon basin points to large-scale deforestation of primary forests effectively shifting sub-regional climate conditions to be significantly drier (Sombroek 1962, 2001). Implications of large-scale deforestation for conservation of plant diversity within aguajales would suggest a regional approach is needed. A regional approach would include maintaining substantial tracks of primary forest around aguajales as opposed to just fencing off aguajales from development.

Rapid loss of neotropical habitat where wild Vanilla species occur supports urgency in documenting valuable wild genetic resources in Vanilla (Lubinsky et al. 2008b). We provide evidence for an auto-fertilizing Vanilla. Discovering the underpinnings of genetic and environmental conditions that bring about this breeding system strategy in the individuals studied, could be useful in breeding programs for improving vanilla yields via autofertilization. This demonstrates the need to conserve wild neotropical Vanilla species as most life history data on these species is completely unknown.

Acknowledgments The authors thank Dr. William E. Walton for advise on statistical analysis. We also thank Dr. Nigel Pitman for field assistance at the Los Amigos Research Station.

Open Access This article is distributed under the terms of the Creative Commons Attribution Noncommercial License which permits any noncommercial use, distribution, and reproduction in any medium, provided the original author(s) and source are credited.

\section{References}

Adams CD (1972) Flowering plants of Jamaica. University of the West Indies, Mona, Jamaica

ATRIUM (2007) http://atrium.andesamazon.org/meteo_ station_list.php. Accessed 9 May 2007

Borhidi A (1996) Phytogeography and vegetation ecology of Cuba. Janus Pannonius University Pécas, Hungary

Cameron K, Soto Arenas MA (2003) Vanilloideae. In: Pridgeon AM, Cribb PJ, Chase MW, Rasmussen FN (eds) 
Genera Orchidacearum, vol 3, Orchidoideae, part 2, Vanilloideae. Oxford University Press, Oxford, pp 281-334

Catling PM (1990) Auto-pollination in the Orchidaceae. In: Arditti J (ed) Orchid biology reviews and perspectives, vol 5. Timber Press, Portland, pp 121-158

Christenson EA (1995) The long-lost Vanilla bicolor. Am Orchid Soc Bull 64:844-847

Engel EC, Irwin RE (2003) Linking pollinator visitation rate and pollen receipt. Am J Bot 90:1612-1618

Garay LA, Sweet HR (1974) Orchidaceae. In: Howard RA (ed) Flora of the lesser Antilles: leeward and windward Islands. Harvard University, Massachusetts, pp 1-228

Householder JE (2007) Diversity, natural history, and conservation of Vanilla of Madre de Dios, Peru. Masters Thesis, Texas Christian University, Fort Worth, USA

Kocyan A, Endress PK (2001) Floral structure and development of Apostasia and Neuweidia (Apostasioideae) and their relationships to other Orchidaceae. Int J Plant Sci 162:847-867

Lubinsky P, Van Dam M, Van Dam A (2006) Pollination of Vanilla and evolution in Orchidaceae. Lindleyana 75:926-929

Lubinsky P, Cameron KM, Molina MC, Wong M, LepersAndrzejewski S, Gomez-Pompa A, Kim SC (2008a) Neotropical roots of a Polynesian spice: the hybrid origin of Tahitian vanilla, Vanilla tahitensis (Orchidaceae). Am J Bot 95:1040-1047
Lubinsky P, Bory S, Hernandez Hernandez J, Kim SC, GomezPompa A (2008b) Origins and dispersal of cultivated Vanilla (Vanilla planifolia Jacks. [Orchidaceae]). Econ Bot 62:127-138

Nielsen LR (2000) Natural hybridization between Vanilla claviculata (W.Wright) Sw. and V. barbellata Rchb.f. (Orchidaceae): genetic, morphological, and pollination experimental data. Bot J Linn Soc 133:285-302

Okada H, Kubo S, Mori Y (1996) Pollination system of Neuwiedia veratrifolia Blume (Orchidaceae, Apostasioideae) in the Malesian wet Tropics. Acta Phytotaxon Geobot 47:173-181

Pyke GH, Pullin HR, Charnov EL (1977) Optimal foraging: a selective review of theory and tests. Q Rev Biol 52:137-156

Sombroek WG (1962) Reconnaissance soil survey of the Guamá-Imperatriz area (area along the upper part of the Belém-Brasilia highway). Mimeo report of SPVEA/SUDAM, Belém and FAO, Rome, Italy

Sombroek W (2001) Spatial and temporal patterns of Amazon rainfall consequences for the planning of agricultural occupation and the protection of primary forests. Ambio 30:388-396

van der Pijl L, Dodson CH (1966) Orchid flowers: their pollination and evolution. University of Miami Press, Coral Gables

Werkhoven MCM (1986) Orchids of Suriname. Vaco, Paramirabo, Suriname 